\section{Research councils struggling in straitjacket of government rules}

\section{London}

THE system of science funding in Britain is hampering the efforts of the research councils to make more efficient use of scarce resources in the face of declining government support. So much was made clear last week with the publication of the annual reports of the research councils for science and engineering (SERC), the natural environment (NERC) and agriculture and food (AFRC). Although the heads of the councils were keen to point out the year's achievements, the reports contain little to suggest that a revitalization of academic science is in sight.

SERC chairman Professor Bill Mitchell describes 1986-87 as a year of "major achievements and some frustrations". One of the persistent frustrations is the council's vulnerability to sudden large fluctuations in funding demands that are outside its control. Last year's fall in the value of sterling left SERC with a shortfall of $£ 20$ million for international subscriptions, while a high pay settlement for scientific staff will cost SERC an extra $£ 10.2$ million in the current year. Government provided the extra money, but the system is not conducive to good management practice, says Mitchell.

Another frustration was the council's failure to obtain full international partners for the spallation neutron source ISIS at the Rutherford Appleton Laboratory, which has put in serious doubt Britain's ability to become a member of the European Synchrotron Radiation Facility (see page 198 for more synchrotron news). SERC cannot afford the subscription on current budget forecasts, and the decision now rests with the government.

Mitchell made clear his enthusiasm for interdisciplinary university research centres, but berated the Advisory Board for the Research Councils (ABRC), whose recent advice to the government on the strategic organization of science called for the proportion of SERC's contribution to basic, curiosity-driven science to be 20 30 per cent of its total spend. Mitchell is adamant that a figure of $35-40$ per cent, with the remainder on strategic programmes, is the minimum necessary to maintain a viable science base. He accused ABRC of being "apparently prepared to acquiesce in the erosion of basic science". Mitchell's 60-40 split between strategic and basic research precludes an annual subscription to CERN (the European Organization for Nuclear Research) of the present $£ 55$ million, from SERC's total budget of $£ 350$ million. CERN member states are at present considering recommendations that would reduce administration costs by around 15 per cent. Even if Britain agrees that such a saving is sufficient to secure its continued membership, other member states may well prefer to see the money reinvested rather than cut from the budget.

For NERC, increased dependence on funds from contract work is causing problems. The bulk of NERC's commissioned research comes from government departments which paid a total of $£ 25$ million to the council last year. NERC's complaint is that contracts arise only sporadically and are usually short-term, linked to immediate problem-solving. According to NERC chairman Hugh Fish, research teams need to be maintained during the periods between contracts, with the result that NERC effectively subsidizes the work. Further, under Treasury rules, NERC is prohibited from making a profit on the work. Fish claims that "some departments are not now prepared to pay the full economic costs of commissioned work . in effect NERC is forced as a more or less captive contractor to reduce its contract prices to levels which, by all the normal operating rules, are unacceptable".

Income from services to industry approached $£ 10$ million, a threefold increase on 1983-84 figures. But NERC has shelved plans to create a company in the private sector to take over its commercial activity: government accounting practices do not allow sufficient management flexibility to run a business effectively.

For AFRC a turbulent period of restructuring is approaching completion, with its former 27 institutions being regrouped into eight. During the year, 401 permanent posts were lost, with 150 compulsory redundancies, bringing the total workforce to 5,275. Earnings from external sources reached $£ 10$ million, the target set for 1990. The Ministry of Agriculture says agricultural research will be reduced by $£ 5$ million in $1989-90$ and $£ 10$ million in 1990-91; part of this will almost certainly hit AFRC. AFRC's acting secretary, Professor John Hearn, says the council will be unable to withstand further cuts without damaging its scientific capability beyond repair: "industry will not invest in a lacerated research service".

As AFRC seeks more money from commercial sources, its long-standing arrangement with the Agricultural Genetics Company (AGC) is coming under scrutiny. AGC, a private company, was set up in 1983 and given the first option to exploit certain plant biotechnology discoveries made by AFRC. Difficulties with the relationship arise when outside parties approach AFRC with contracts to work in areas that fall under the AGC agreement. Simon Hadlington

\section{New centre to exploit research} London

A potentially influential new body charged with alerting Britain's government, industry and research community to emerging areas of exploitable technology was formally launched last week. The Centre for Exploitation of Science and Technology (CEST) will be located at the Manchester Science Park, adjacent to the University of Manchester. Initial funding, for a five-year period, has been raised from 18 founding companies, including ICI, Rolls-Royce and Smiths Industries, each contributing $£ 250,000$. The taxpayer has given a further $£ 1$ million.

The idea for the centre grew from a report by the government's Advisory Committee on Applied Research and Development (ACARD, which has since broadened its remit and been renamed the Advisory Council for Science and Technology, ACOST), which concluded that a forum was needed for research planning (Nature 321, 105; 1986).

A chief executive for the centre has yet to be appointed, but Sir Robin Nicholson, chairman of the CEST steering committee and former science adviser in the Cabinet Office, predicts that the centre will be functioning before the end of the year.

CEST will have a core group of about 12 professional staff who will, says Nicholson, spend their time assessing, monitoring and evaluating scientific research worldwide. They will collate information and produce "very high quality reports in specific areas of science and technology and specific areas of industrial need"

Mr John Fairclough, the present science adviser in the Cabinet Office, emphasized the centre's importance in a new "climate of change" where traditional barriers between industrialists and academics should be removed. Both Fairclough and Nicholson insist that the centre's formation is not an attempt to force universities to do more applied research. Nicholson suspects that as the centre's information becomes widely available, industry will recognize areas of strategic importance and respond spontaneously.

CEST will have the ear of the government through its links with ACOST. Academic representation on the steering committee is in the person of Sir David Phillips, chairman of the Advisory Board for the Research Councils.

Thirteen institutions were invited to bid to house the new centre. The successful proposal came from a consortium of nine universities and polytechnics in the NorthWest. CEST will have access to the consortium's library and computer facilities, as well as considerable academic support. Simon Hadlington 